\title{
BENEFICIOS $¿$ PODEMOS HABLAR DE ELLO EN EL USO DE LOS MEDIOS ELECTRÓNICOS COMO CONSECUENCIA DEL SARS-COV-2?
}

\section{BENEFITS. CAN WE TALK ABOUT THEM IN THE USE OF THE ELECTRONIC MEDIA AS A CONSEQUENCE OF SARS-COV-2?}

\author{
David Suárez-Rivero \\ Universidad Autónoma de Tlaxcala, México \\ darisua@gmail.com
}

Recibido: 16 de mayo de 2020 / Aceptado: 25 de mayo / Publicado: 20 de junio de 2020

\begin{abstract}
Resumen:
En el presente artículo muestro que, como consecuencia del SARS-CoV-2, ha habido no solamente perjuicios, sino también beneficios, a saber: el incremento de confianza y responsabilidad por parte de los ciudadanos en los medios electrónicos, y la oportunidad que estos les han brindado de continuar su vida social, emocional y laboral en el confinamiento. Particularmente, sostengo que, aunque los medios electrónicos han sido usados en muchas ocasiones para crear miedo y control en la población, puede dárseles un uso diferente, el cual informe, responsabilice y establezca relaciones benéficas.
\end{abstract}

Palabras clave: SARS-CoV-2. Beneficio. Confianza. Responsabilidad. Medios electrónicos.

\begin{abstract}
:
In this paper I show that as a consequence of SARS-CoV-2 there have been not just damages but also benefits, namely: the increase of trust and responsibility by the citizens on the electronic media, and the opportunity that it has given to the human beings of continuing their social, emotional and working life. Particularly, I support that, although the electronic media has been used in some occasions to misinform, create fear and control in the population, they might be used differently, promoting with them trusted information, responsibility and establishing beneficial relationships.
\end{abstract}

Keywords: SARS-CoV-2. Benefit. Trust. Responsibility. Electronic media. 


\section{Introducción}

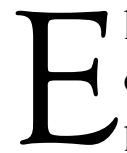

1 SARS-CoV-2 ha afectado al ser humano en ámbitos diversos. En la economía, por ejemplo, la producción se ha reducido por la suspensión parcial o completa de actividades. Como consecuencia, un considerable número de empleados y trabajadores han sido despedidos. Muchos otros, que laboran de manera independiente, han tenido pérdidas, al tener que cerrar sus establecimientos o reducir las ventas, afectando en todos los casos a las familias.

En muchos países -como Brasil, España o Reino Unido- el sector de salud se ha visto en riesgo de un probable colapso, debido a que no pueda atender al número creciente de personas que van ascendiendo en la adquisición del virus. La razón de ello es que los más delicados requerirían atención especializada, la cual implicaría un lugar donde acogerlos y un sin número de medicamentos o ventiladores para ayudarlos a superar la convalecencia.

La educación y la investigación de las instituciones públicas y privadas también ha sido afectada, ya sea por la suspensión de clases presenciales o de experimentos que requieren plazos de tiempo e instrumentos especializados, por la movilidad académica -estadías, conferencias, congresos- o por el cierre de bibliotecas y hemerotecas.

Donde se lamenta más la pérdida, sin embargo, es en el gran número de personas que han muerto a nivel mundial, muchos de ellos adultos mayores o con enfermedades crónicas. Todo esto, y lo anterior, muestra los perjuicios que se han producido en los seres humanos. Pese a ello, surgen al menos dos preguntas difíciles de evitar, a saber: ¿podemos hablar de beneficios como consecuencia del SARS-CoV-2? Particularmente, ¿podemos hablar de ello en el uso de los medios electrónicos como resultado del virus?

En el presente artículo proporciono argumentos y evidencias que muestran que podemos responder afirmativamente a las preguntas anteriores. Particularmente, muestro que el incremento de confianza y el uso responsable por parte de los ciudadanos en los medios electrónicos son dos beneficios importantes que ha traído como consecuencia el SARS-CoV-2. Aunque es verdad que estos han sido usados muchas veces para crear miedo y control en 
la población ${ }^{1}$, puede dárseles un uso diferente, el cual informe, responsabilice y establezca relaciones benéficas entre los seres humanos.

Para mostrar mi tesis anterior, procederemos en las secciones del artículo de la siguiente manera: en la sección ¿Qué es un beneficio? analizaremos los conceptos beneficio y perjuicio. Polemizaremos si al uso reciente de los medios electrónicos se le puede dar uno que sea confiable y responsable en la sección Medios electrónicos y comunicación. En la sección Confianza exploraremos dicho concepto. Luego, mostraremos los beneficios que ha traído el SARSCoV-2 en la sección Formas innovadoras de relaciones humanas.

Finalizaremos evaluando contrargumentos diversos en las secciones Objeción primera, Objeción segunda y Objeción tercera, proporcionando respectivas defensas en Respuesta a objeción primera, Respuesta a objeción segunda y Respuesta a objeción tercera, mostrando que hay un beneficio reciente en el uso de los medios electrónicos, como una forma de continuar la vida social, laboral y emocional frente al SARS-CoV-2.

\section{¿Qué es un beneficio?}

Pensemos en la oración siguiente:

(1) Domingo murió de un paro cardíaco.

Si escuchamos proferir la oración (1) en un contexto donde Casandra era fuertemente maltratada por Domingo, diremos que Casasndra fue liberada de su verdugo. Sin embargo, si la escuchamos proferir esa misma oración en un contexto donde Domingo era el que proveía económicamente a su familia, compadeceríamos profundamente a Casandra. En el primer caso, Casandra obtiene un beneficio, el cual no se da en el segundo, resultando lo contrario.

Supongamos, sin embargo, que Casandra es economista, profesión que no ejerce, al ser impuesto por su marido, para dedicarse a cuidar la casa y los hijos. En este contexto, al escuchar proferir (1), diremos que Casandra podrá ejercer exitosamente, obteniendo así un beneficio, el de realizarse como profesionista.

Reflexionemos ahora acerca de la siguiente oración:

1 Confróntese la sección Medios electrónicos y comunicación, donde desarrollo y proporciono evidencia sobre esta idea. 
(2) Elizabeth II fue nombrada Reina de Inglaterra.

$\mathrm{Si}$ (2) es proferida en un contexto donde George VI ha muerto y, como resultado de ello, Elizabeth II es nombrada reina, diremos que habría preferido no serlo para continuar teniendo a su padre vivo. Paradójicamente, en este caso, el beneficio de ser nombrada reina viene acompañado del perjuicio obtenido por la muerte de George VI.

De los anteriores ejemplos podemos establecer lo siguiente:

(B) Un beneficio es la ganancia, el bien, la utilidad o el provecho obtenido a partir de un hecho ${ }^{2}$.

Este beneficio obtenido no excluye posibles daños o perjuicios como resultado del mismo hecho, tal como lo muestra el caso de la oración (1) y (2), donde Casandra puede ejercer su profesión al quedarse sin solvencia económica por la muerte de su marido, o Elizabeth II es nombrada reina como resultado de la pérdida de George VI. Así:

(P) Un perjuicio es la pérdida, el mal, el daño, la inutilidad o la inconveniencia obtenida a partir de un hecho.

(B) y (P) pueden ser aplicadas no solamente a personas, sino también a otros seres vivos y objetos no animados. Por ejemplo, pensemos en la oración:

(3) Lleva tres días lloviendo a cántaros.

Si escuchamos proferir la oración (3) en un contexto donde había una sequía, y los animales salvajes morían como resultado de ello, diremos que la fauna podrá restablecerse. Sin embargo, en una situación diferente con un

2 En el artículo abordo el concepto beneficio y no beneficencia, este último empleado en Ética, en el principio de beneficencia. Una diferencia importante es que el primer término es entendido como una ganancia o bien, mientras que el segundo como una acción realizada para el bien de alguien o algo. Aunque una acción benéfica trae un beneficio, este es un concepto mucho más básico que no implica necesariamente una acción. Este concepto básico es el estudiado en esta sección, y en el resto del artículo.

Para tener una comprensión del concepto beneficencia, y su discusión en Ética, pude consultarse: Beauchamp, Tom. "The Principle of Beneficence in Applied Ethics", In The Stanford Encyclopedia of Philosophy (Spring 2019 Edition). Edited by Edward N. Zelta, 2019. https://plato.stanford.edu/entries/principle-beneficence/. Agradezco a un dictaminador haberme pedido referencias bibliográficas sobre el principio de beneficencia, así como la clarificación del principio de beneficio que uso en el artículo, y otras clarificaciones que mejoraron una versión previa del presente artículo. 
diluvio, señalaremos que la fauna está en peligro. En el primer caso, esta será beneficiada, pero perjudicada en el segundo.

Por lo tanto, un beneficio es algo positivo obtenido como resultado de un hecho, mientras que un perjuicio es algo negativo obtenido de la misma manera. En muchos casos, como el de las oraciones (1) y (2), ese mismo hecho puede generar beneficios y perjuicios, no siendo el caso de la oración (3).

\section{Medios electrónicos y comunicación}

¿Podemos hablar de beneficios en el uso de los medios electrónicos como consecuencia del SARS-CoV-2? Comencemos con resultados desfavorables.

Recientemente, se ha discutido en la prensa internacional el uso inadecuado que se ha dado a los medios electrónicos. Se argumenta, por ejemplo, que el actual gobierno de los Estados Unidos de América se sirvió de una campaña que generó lo que ahora se llaman fake news, divulgándolas por plataformas populares como Facebook, Instagram o las amplias páginas habidas en Internet, para popularizar a Donald Trump, con el objetivo de hacer que cierto sector mayoritario de la población se inclinara por él al momento de la elección ${ }^{3}$. Se sostiene también que en lugar de fake news, se usan interpretaciones de los hechos con las cuales se ayuda a favorecer a ciertos gobiernos, como el que China generó el SARS-CoV-2 en un laboratorio ${ }^{4}$-para debilitar, quizá, a nivel mundial, el sector financiero-.

Lo interesante en estas discusiones es que la información que se defiende es muy difícil de corroborar, generando en la población sentimientos y pensamientos de desazón que pueden conducir a acciones no meditadas ${ }^{5}$. Esto parece evidenciar que los medios electrónicos no sirven sino para mal informar, controlar y manipular grupos de personas para objetivos desalmados

3 Cfr.: Olvier Bullough, "Collusion by Luke Harding review - did Russia help Trump become president?”, The Guardian, December 18, 2017. https://www.theguardian.com/books/2017/dec/18/ collusion-luke-harding-review-how-russia-helped-trump-win-the-white-house

4 D. Alandete, R. Sánchez y I. Salazar, "Máxima presión sobre China para que dé explicaciones del origen de la pandemia”, ABC, mayo 6, 2020. https://www.abc.es/internacional/abci-maxima-presion-sobre-china-para explicaciones-202005041948_noticia.html

5 Cfr.: Ian Sample, “Covid-19: the psychology of conspiracy theories”, The Guardian, mayo 5, 2020. https://www. theguardian.com/science/audio/2020/may/05/covid-19-the-psychology-of-conspiracy-theories 
y egoístas. Así, como resultado, se ha concluido que estos no son sino un instrumento de poder para beneficiar al capitalismo ${ }^{6}$.

Por mor del argumento, asumamos que lo anterior es cierto, que el sistema, cualquiera que este sea, se sirve de los medios electrónicos para manipular, infundir miedo y dominar a la población. ¿Se sigue de esto, sin embargo, que los medios electrónicos sirven exclusivamente para ello?

Argumentaré que no se sigue dicha conclusión. Defenderé que, aunque los medios electrónicos han sido usados muchas veces para mal informar, crear miedo y control en la población, podemos darle un uso diferente, el cual informe, responsabilice y establezca relaciones benéficas.

\section{Confianza}

La confianza es uno de los elementos fundamentales en las relaciones humanas. Sin ella, la comunicación entre seres amados, personas cercanas o colegas en el trabajo sería limitada. Con la confianza, por el contrario, las relaciones se tornan cercanas. Pensemos, por ejemplo, en el siguiente caso:

(4) Desde hace dos años Jorge sale por las noches a cenar con Narriman.

Supongamos que Jorge está casado. Su esposa escucha proferir (4) a un colega de él, informándole que su marido la engaña. Al cerciorarse de ello, la esposa queda estupefacta, dado que Jorge había informado durante todo ese tiempo que no se presentaba a cenar por cuestiones laborales, quedándose en la oficina todas las noches. Dado este contexto, la confianza que tiene la ella en él queda afectada, repercutiendo en la comunicación establecida entre ellos. Deciden divorciarse, entonces, por ello.

Pongamos un caso diferente:

(5) Josefa se ducha dos veces a la semana.

Digamos que Josefa escucha a su vecina proferir (5), con la que conversa cada día al regar su jardín, entre un grupo de conocidas. Aunque (5) es verdadera, a Josefa le disgusta que su vecina, con la cual había establecido una relación de cordialidad, hable de sus hábitos higiénicos. Como se siente

6 Cfr.: John Naughton, “The goal is to automate us': welcome to the age of surveillance capitalism”, The Guardian, enero 20, 2020. https://www.theguardian.com/technology/2019/jan/20/ shoshana-zuboff-age-of-surveillance-capitalism-google-facebook 
disgustada, Josefa decide mantener una relación menos estrecha con su vecina al limitar su confianza.

Empleemos ahora en un contexto diferente la oración (4). Digamos que el jefe de Jorge, no necesariamente el mismo del ejemplo anterior, escucha proferir dicha oración a un empleado de confianza. Narriman es una ejecutiva importante de la compañia con la que colabora la de Jorge. Como resultado de dichas cenas, Narriman apoya los proyectos de la empresa de Jorge, ayudándola a generar ganancias económicas supremas. El jefe de Jorge, al enterarse de ello, refuerza aún más su confianza en él, haciéndolo directivo.

Como podemos apreciar, la confianza funge un papel importante en la toma de decisiones y en la ejecución de acciones. A partir de esto, podemos establecer lo siguiente:

(C) Las relaciones humanas son mejores a partir de la confianza.

El concepto de confianza involucra grados de confianza. Pensemos en el jefe de Jorge: aunque su confianza estaba establecida, esta aumentó cuando supo que Jorge establecía redes sociales para beneficiar a la empresa. No es el caso de la esposa de Jorge, el del primer ejemplo, que perdió la confianza en él. En el caso de Josefa, aunque sigue habiendo confianza, ahora es limitada, después de que sabe que su vecina no es prudente en la información que transmite. (C) recoge este grado cuando establece que las relaciones humanas son mejores a partir de la confianza.

\section{Formas innovadoras de relaciones humanas}

Uno de los beneficios que se ha generado como consecuencia del SARSCoV-2 es la confianza que los ciudadanos han incrementado en el uso de los medios electrónicos ? Ello puede deberse a lo siguiente: (i) la orientación que han proporcionado los gobiernos de los países, a través de los medios de comunicación tradicionales, a usarlos correctamente ${ }^{8}$; (ii) la orientación

7 Cfr.: Kleis Nielsen, Rasmus, Richard Fletcher Nic Newman. J. Scott Brennen y Philip N. Howard. "Navigating the "infodemic": how people in six countries Access and rate news and information about coronavirus". Reuters Institute. Acceso el 6 de mayo 2020. https://reutersinstitute.politics.ox.ac.uk/ infodemic-how-people-six-countries-access-and-rate-news-and-information-about-coronavirus

8 Cfr.: Raúl Magallón Rosa, "Periodismo abierto y responsabilidad compartida ante la crisis del COVID-19”, The Conversation, arzo 16, 2020. https://theconversation.com/ periodismo-abierto-y-responsabilidad-compartida-ante-la-crisis-del-covid-19-133801 
que han proporcionado jóvenes a personas no familiarizadas con ellos, ya sea en casa o en centros que brindan dicho apoyo ${ }^{9}$; o (iii) la información que han proveído las instituciones públicas y privadas por a través de sus páginas oficiales ${ }^{10}$.

Esta orientación e información ha estado destinada principalmente, pero no exclusivamente, a enseñar a identificar a los ciudadanos cuándo una página electrónica es fiable, cuándo es conveniente comparar o corroborar información recibida, y a qué medios hay que otorgarles credibilidad. Con ello, cada vez más personas han aprendido a revisar y seleccionar información, teniendo la capacidad de poder discernirla.

Un segundo beneficio es que esta orientación ha impulsado el uso responsable de los medios electrónicos, al enseñar que solamente aquella información fidedigna debe ser leída y divulgada ${ }^{11}$. De no hacerse ello, como razón principal, se corre el riesgo de confundir a la población sobre fenómenos que afectan al mundo en general, como lo es el SARS-CoV-2.

Así, no solamente los ciudadanos han incrementado su confianza en el uso de los medios electrónicos a través de la enseñanza otorgada, sino que también han adquirido responsabilidad al poder manejar y difundir la información encontrada y recibida. Como resultado de esto, han surgido de la misma manera los siguientes beneficios.

Los ciudadanos han aprendido que en Facebook no solamente se puede ver y leer información de la vida personal de los individuos, sino que también pueden acceder a páginas informativas relacionadas con religión, arte, política, economía o medio ambiente. Han aprendido a usar Instagram para compartir actividades, recuerdos o nostalgias estando en casa confinados, con el objetivo de acompañar o sentirse acompañados. También han aprendido a tener momentos de ocio a través de los portales abiertos que brindan museos,

Helmuth, Laura. "Tipsheet: Covering the Coronavirus Epidemic EffectivelywithoutSpreading Misinformation”. TheOpenNoteBook. The story behind the best science stories. Acceso el 6 de mayo 2020. https://www.theopennotebook. $\mathrm{com} / 2020 / 03 / 02 /$ tipsheet-covering-the-coronavirus-epidemic-effectively-without-spreading-misinformation/

9 Cfr.: Newcastle City Council. "Skills and business services: Develop your digital skills", newcastle.gob.uk. Acceso el 6 de mayo de 2020. https://www.newcastle.gov.uk/services/libraries-culture/skills-and-business-services/ develop-your-digital-skills-0

10 Cfr.: First Draft. “Too Much Information? Our Guide Can Help”. firstdraftnews.org. Acceso el 6 mayo de 2020. https://firstdraftnews.org/project/too-much-information-a-public-guide/

11 López Doblas, Manuel, Nuria Luque Martín y Amelia Martín Barato. “Medios de Comunicación y COVID-19”. Escuela Andaluza de Salud Pública. Consejería de Salud y Familias. Accesado el 6 de mayo de 2020. https://www.easp. es/web/coronavirusysaludpublica/medios-de-comunicacion-y-covid-19-pautas-para-una-informacion-responsable/ 
galerías, plataformas de cine o revistas. La ganancia que lega esto es que se puede continuar la vida social usando los medios electrónicos. Esto no quiere decir que estase reduzca a estos, sino que parte importante de esta se establece -o se puede establecer- a través de ellos.

Otro de los beneficios resultantes ha sido aprender a usar los medios electrónicos para fines escolares, académicos o de investigación. Las instituciones públicas y privadas siguen ofreciendo educación básica y especializada a través de plataformas electrónicas, Skype, Facetime, Zoom y WhatsApp. Estas plataformas permiten una interacción presencia-digital entre estudiantes y profesores por medios de audios y videoconferencias. Los docentes, asimismo, están aprendiendo estrategias pedagógicas para brindar conocimiento de manera digital. Los alumnos, por su parte, aprenden a ser autodidactas -gestionando su tiempo con la ayuda de familiares, personas cercanas o de manera independiente- a través del acompañamiento electrónico de los profesores. Con lo anterior se muestra que el aprendizaje se puede generar, aun sin asistir a clases presenciales, resultado actual que han tratado de mostrar a lo largo de los últimos años aquellas instituciones que promueven la educación a distancia.

Otro de los beneficios resultantes se ha dado en la vida emocional y sentimental de los ciudadanos. No solamente los jóvenes se comunican ahora de manera electrónica con sus amigos, sino que lo hacen también los adultos y las personas mayores. Es decir, los medios electrónicos han alcanzado un grupo de ciudadanos más amplio, los cuales se habían mantenido reticentes o no tenían los conocimientos apropiados, considerándolos irrelevantes o de poco valor para su vida. Estando confinados, estas personas han comenzado a usar los medios electrónicos para mirarse y sonreírse; para enseñar a los otros la manera de cocinar las recetas legadas por la abuela; para hablar de los miedos, del pasado y del futuro, ya sea con seres queridos, psicólogos o especialistas de índole diversa.

Los medios electrónicos han permitido, por lo tanto, que los seres humanos continúen su vida social, abarcando áreas informativas, educativas y emocionales. Este es el resultado de que los ciudadanos hayan incrementado su confianza en ellos, al haber sido informados, generando responsabilidad también en su uso. Confiando en los medios electrónicos, y siendo responsable en su uso, los ciudadanos comienzan a vivir una realidad virtual que no se 
aleja de la física, sino que la acompaña. Estos son los beneficios que ha traído como consecuencia el SARS-CoV-2.

\section{Objeción primera}

Asumamos por un momento que los beneficios descritos hasta ahora no son sino maneras paliativas -improvisadas y desesperadas- para hacer frente a la gran cantidad de perjuicios que ha traído el SARS-CoV-2. Esto es, estas maneras paliativas, en lugar de ser beneficios, han servido para contrarrestar la pandemia y no para enriquecer la experiencia humana -como aprender, comunicarse y desarrollar todo tipo de actividades virtuales-.

Este es el caso de una anciana que está en cama sin poder caminar y que ama a los bosques. Al no poder salir, uno de sus nietos dibuja una rosa y la coloca en el buró de su cama. Esto, de alguna manera, alegra a la anciana, pero no es claro cómo ese dibujo hace que la experiencia de ella sea mejor o más humana. Quizá algo así está pasando también con el uso de los medios electrónicos en el confinamiento frente al SARS-CoV-2.

\section{Respuesta a objeción primera}

Aceptemos que los beneficios mencionados son maneras paliativas para hacer frente a las consecuencias del SARS-CoV-2. Esto no indica, sin embargo, que estas manera paliativas no sean beneficios y que no enriquezcan la experiencia humana. No hay ninguna incompatibilidad entre "maneras paliativa" y "beneficios". Una manera paliativa de solución es -o puede ser- un beneficio. Es decir, una manera paliativa puede servir para múltiples usos, ya sea para hacer frente a una pandemia o para enriquecer la experiencia humana. Este es el caso de los medios electrónicos, sirven para solucionar situaciones de aislamiento en el confinamiento, pero también sirven para enriquecer la experiencia humana. No hay incompatibilidad entre ello.

Tal es el caso del dibujo de la rosa: sirve para hacer frente al aislamiento de la anciana y la beneficia al traerle un poco de alegría. Este dibujo, sin embargo, es un caso primitivo del uso de la tecnología -el lápiz y la hoja de papel son inventos del pasado-. Actualmente hay recursos sofisticados ${ }^{12}$ que

12 Cfr.: Samuel Gibbs y Keza MacDonald, "Five of the best VR headsets", The Guardian, junio 22, 2020. https://www.theguardian.com/technology/2019/jun/22/ 
podrían hacer que la experiencia de la anciana sea real al caminar por bosques virtuales usando gafas virtuales. Es verdad que ella seguiría en cama sin poder salir, pero la experiencia que tenga usando dichas gafas le traería bienestar y le haría tener una mejor vida.

Este tipo de dispositivos virtuales -como lo puede ser también un dibujo menos sofisticado- cumplen dos funciones: hacer frente al aislamiento -como podría ser el confinamiento frente al SARS-CoV-2 - y traer un beneficio al ser humano -como establecer relaciones afectivas de comunicación-. Ninguno de ellos es incompatible el uno del otro.

\section{Objeción segunda}

A pesar de lo anterior, podríamos argumentar -intentando refutar los principios (B) y (P) - que los conceptos beneficio y perjuicio son significativos solamente en relación y contraste entre ellos, arrojando uno, pero no el otro, según como se den los hechos. Por ejemplo, consideremos una balanza con dos platos bien equilibrados entre ellos. De un lado colocamos trigo, y del otro cebada. Dado que el trigo es mayor, la balanza se inclina hacia su lado y deja por arriba a la cebada. Si quisiéramos decidir cuál es nuestra ganancia en la cosecha, tendríamos que decir que fue el trigo, dado que en la balanza dejó por arriba a la cebada.

Pensemos en otro ejemplo, digamos el maíz. De un lado de la balanza colocamos toda la mazorca que se ha estropeado por los torrenciales que hubo en la temporada, del otro lado colocamos la mazorca que fue salvada. Al momento de sopesar la mazorca comestible de la que no lo es, vemos que la balanza se inclina hacia aquella que quedó estropeada por el agua, dejando muy por encima a aquella que logró salvarse. Diremos, por lo tanto, en este contexto, que no fue un buen año, dado que la cosecha quedó estropeada. De esto podemos desprender lo siguiente:

(R) $x$ es un beneficio solo si, comparada con una serie de perjuicios $y$, $x$ siempre es superior a $y$; de otra manera, si $y$ supera a $x$, entonces $x$ no es un beneficio.

five-best-vr-headsets-oculus-quest-rift-s-htc-vive-pro-playstation-nintendo-labo-switch

MarkBrown, "Weirdandwonderfulways togetthrough the Covid-19lockdown", TheGuardian, marzo 23, 2020. https:// www.theguardian.com/world/2020/mar/23/weird-and-wonderful-ways-to-get-through-the-covid-19-lockdown Laura Feinstein, “'Beginning of a new era': how culture went virtual in the face of crisis”, The Guardian, abril 8, 2020. https://www.theguardian.com/culture/2020/apr/08/art-virtual-reality-coronavirus-vr 
(R) puede aplicarse al caso del SARS-CoV-2: si quisiéramos ofrecer un diagnóstico sobre sus beneficios y perjuicios, tendríamos que recurrir a una balanza imaginaria, sopesando las ganancias y las pérdidas. Una de los mayores daños que ha dejado el virus es la muerte de más de 482808 personas a la fecha (25/6/2020); la disminución económica en la producción y, como consecuencia, el desempleo; y la inversión, a pesar de la falta de recursos, en hospitales ambulatorios y medicamentos.

Si pusiéramos en la balanza, en uno de sus extremos, dicha cantidad de personas, de pérdida económica y de inversión monetaria, y en el otro el incremento de confianza y el uso responsable por parte de los ciudadanos en los medios electrónicos, y la oportunidad que estos les han brindado, como resultado de los primeros, de continuar su vida social, emocional y laboral, la balanza se inclinaría seguramente hacia el lado de los muertos, la pérdida económica y la inversión, dejando muy por encima a los beneficios que han obtenido los seres humanos usando los medios electrónicos responsablemente. Si esto es así, no podríamos hablar de beneficios, sino más bien de perjuicios como consecuencia del SARS-CoV-2.

\section{Respuesta a objeción segunda}

Aunque podemos aceptar las premisas, la conclusión de la objeción anterior no se sostiene, al menos no categóricamente, al mantener que no se puede hablar de beneficios, sino únicamente de perjuicios como consecuencia del SARS-CoV-2. Es decir, aunque podría ser cierto que los conceptos de beneficio y perjuicio son significativos en relación y en contraste entre ellos, no es verdad que se arroje exclusivamente uno, pero no el otro, según como sean los hechos. Para mostrarlo, consideremos lo siguiente.

Dijimos que el concepto de confianza es gradual. Según el contexto, una persona puede tener confianza en otra con mayor o menor intensidad. En el caso de la oración (4), la confianza de la esposa de Jorge desapareció; en el otro ejemplo, la del jefe aumentó. En el caso de la oración (5), la confianza de Josefa hacia su vecina disminuyó.

La diferencia entre la esposa de Jorge y Josefa es que, aunque Josefa aún confía mínimamente en la vecina, la esposa de Jorge no confía más en él. Aunque la confianza de la esposa de Jorge podría regresar, sería muy difícil pensar 
en ello. Pero no sería difícil pensar en que Josefa aumente su confianza hacia su vecina, dado que aún tiene una mínima. Esta es la ganancia de la vecina de Josefa frente a Jorge, que aún se puede confiar en ella, pero no más en Jorge. Es decir, aún hay algo de confianza que podría incrementar.

Con los conceptos de beneficio y perjuicio sucede lo mismo: ambos son graduales. Si bien es cierto que, en el primer ejemplo, hay poca cebada y bastante trigo, siendo este el beneficio obtenido, también podríamos hablar de la cebada como un beneficio -menor, quizá- que puede aun así otorgarnos un bien diferente a la del trigo. Podríamos, digamos, obtener cierto bien económico al venderla, el cual no se obtendría, sino hubiera habido cebada. Esta es la ganancia, este es el beneficio.

En el caso del maíz, aunque la pérdida es mayor, aun así, podríamos hablar de una ganancia mínima, la de haber obtenido cierto número de mazorcas, la cual podríamos usar para alimentar a nuestros hijos algunos días, consiguiendo quizá nuevas oportunidades económicas en dicho periodo. Esta es la ganancia, este es el beneficio.

Con el SARS-CoV-2 sucede lo mismo: aunque el perjuicio es mayor -el de la pérdida de una vasta cantidad de seres humanos y un considerable número de recursos económicos-, aun así podemos hablar de beneficios, a saber: el incremento de la confianza y el uso responsable por parte de los ciudadanos en los medios electrónicos, y la oportunidad que estos les han otorgado, como resultado de lo primero, de continuar su vida social, emocional y laboral. A partir de ellos, los ciudadanos pueden obtener nuevos bienes que les puedan permitir la creación de mejores condiciones, tanto económicas, políticas, psicológicas y sentimentales.

\section{Objeción tercera}

Víctor Cantero-Flores ${ }^{13}$ duda de que el SARS-CoV-2 proporcione beneficios. El argumento que proporciona es el siguiente.

Consideremos la siguiente oración:

(6) Al menos algo bueno hay en todo esto.

13 Víctor Cantero Flores es profesor de la Universidad del Caribe, Cancún, México. Le agradezco esta objeción tercera, y la objeción primera, y otros comentarios sustanciales que me hicieron replantear las principales ideas de esta investigación. 
Imaginemos que Juan es asaltado, golpeado, insultado y humillado. Afortunadamente, Juan no muere y una ambulancia logra rescatarlo. Cuando lo recogen para llevarlo al hospital, encuentra una gema preciosa que alguien dejó caer accidentalmente. Guarda la gema y profiere la oración (6).

Consideremos ahora el siguiente caso. Pedro es una persona egoísta, codiciosa y malvada, pero amargada y triste. Sin embargo, en algún punto de su vida le da cáncer. Esto le hace cambiar drásticamente su manera de pensar y actuar: ayuda a mucha gente, tiene muchos amigos y, a pesar de la enfermedad, se siente feliz y satisfecho. Pedro muere rodeado de todas las personas que lo quieren y admiran, y en sus últimas palabras profiere la oración (6).

En estos ejemplos, argumenta Cantero-Flores, hay un sentido en el que encontrar la gema preciosa -en el caso de Juan- o adoptar una manera de pensar y actuar humanitario -en el caso de Pedro- es una consecuencia del asalto o del cáncer. Asimismo, encontrar esa gema preciosa o adoptar una manera de pensar y actuar humanitario representa un beneficio -Juan puede vender la gema y Pedro obtener grandes amigos-. Además, es cierto que la cantidad de perjuicios que se obtuvieron superan los beneficios resultantes del asalto o del cáncer. Todo esto cumple con todas las condiciones que se han presentado en este artículo a favor de que algo sea un beneficio.

A pesar de lo anterior, continúa Cantero-Flores, resulta extraño decir que encontrar una gema preciosa o adoptar una manera de pensar y actuar humanitario es un beneficio del asalto o del cáncer. Para poder aseverar esto deberíamos poder decir algo como lo siguiente:

"iQué bueno que me asaltaron o qué bueno que me dio cáncer! Si no me hubieran asaltado o si no me hubiera dado cáncer, no habría encontrado esta gema preciosa o no habría adoptado esta manera de pensar y actuar humanitario. Si pudiera elegir volver a pasar esa experiencia, la viviría de nuevo con tal de encontrar la gema preciosa o adoptar el pensar y actuar humanitario”.

Esto, no obstante, es muy raro, asegura Cantero-Flores, especialmente considerando la gran cantidad de pérdidas que tuvieron dichas personas.

En palabras precisas, lo que Cantero-Flores defiende es lo siguiente:

(P) Para poder decir que $\mathrm{x}$ es un beneficio derivado de una situación s, debe ser preferible que la situación s ocurra en contraste con el hecho de que s no ocurra. 
En el ejemplo de Juan, la situación "hay asalto" debe ser preferible a la situación "no hay asalto". La razón es que la situación "hay asalto" trae el beneficio de encontrar una gema preciosa. Si esto no ocurre, entonces encontrar esa gema preciosa no es un beneficio. Juan, claramente, preferiría no ser asaltado, incluso si eso significa no encontrar la gema preciosa.

En el caso de Pedro, la situación "hay cáncer" deber ser preferible a la situación "no hay cáncer". La razón es que la situación "hay cáncer" trae el beneficio de adoptar una manera de pensar y actuar humanitario. Si esto no ocurre, entonces adoptar una manera de pensar y actuar humanitario no es un beneficio. Sin embargo, Pedro preferiría no tener cáncer, incluso si eso significa morir amargado, triste y sin amigos.

En el caso del SARS-CoV-2 ocurre algo similar, concluye Cantero-Flores. Para que podamos decir que el virus trajo beneficios, en particular los mencionados a lo largo de este artículo, debe ser posible decir que el que halla SARS-CoV-2 es preferible al hecho de que no lo halla. Pero esto es muy raro. Seguramente, casi todas las personas preferirían que no hubiera existido.

\section{Respuesta a objeción tercera}

Debe ser preferible que la situación $s$ ocurra en contraste con el hecho de que $s$ no ocurra para poder decir que $x$ sea un beneficio derivado de $s$. ¿Qué significa, sin embargo, "debe ser preferible que algo ocurra a que no ocurra”? ¿Cuál es la relación que tiene "la preferencia” con "el hecho" y con que "algo sea un beneficio" de ese hecho? ¿Es correcto decir que "el preferir que algo ocurra a que no ocurra" legitima a "la obtención de un beneficio"? Por contraste, ¿es correcto decir que "el preferir que algo no ocurra a que ocurra" legitima a "la obtención de un perjuicio" ¿Si no se prefiere una situación de la que se obtuvo algo, entonces no puede contar como beneficio o perjuicio?

El que algo sea preferible -o que sea deseado vivirlo nuevamente- no hace que un beneficio obtenido no lo sea. Es decir, los beneficios o perjuicios que se derivan de los hechos son independientes de las preferencias o deseos de los sujetos. Los beneficios o perjuicios obtenidos son resultados de hechos. El preferir o desear que estos hechos sean diferentes no hace de los beneficios perjuicios, ni de los perjuicios beneficios. Los hechos ocurren, y puede encontrarse en ellos beneficios y perjuicios, sin que influya en ello preferencias o deseos. 
Claramente, Pedro no prefirió el cáncer para mudar de pensamiento y acción con tal de poder obtener el beneficio de los amigos. Pudo conseguirlos prefiriendo otros hechos menos dolorosos, digamos por un sueño: soñando que morir solo no era bueno, y que para ello, tenía que cambiar de manera de pensar y actuar; o por un pensamiento al azar: levantándose, y decidiendo cambiar su manera de pensar y actuar hacia las personas, viendo en ello, la opción de generar amistades.

No hay conexión alguna entre el cáncer, el sueño o el pensamiento azaroso con las preferencias o deseos de Pedro para conseguir los beneficios o los perjuicios derivados de ellos. Estos están ligados directamente con ciertos beneficios y perjuicios, y de manera indirecta con las preferencias y deseos de Pedro. Pero está en él, una vez dados, cualquiera de esos hechos, descubrir los beneficios o los perjuicios que se derivan de ellos. Por ello:

$(\mathrm{N})$ "Debe ser preferible que $s$ ocurra" no tiene relación alguna con "el beneficio o perjuicio $x$ derivado de $s$ "

Pensemos, por ejemplo, en el caso de la oración (3): el restablecimiento o peligro de la fauna debido a las intensas lluvias no obedece a las preferencias o los deseos de los animales. El restablecimiento o peligro depende de factores externos a ellos, particularmente, de la lluvia y de las condiciones de la naturaleza, los cuales pueden beneficiar o perjudicar a la fauna.

Lo mismo sucede con el SARS-CoV-2: sus beneficios o perjuicios no obedecen a preferencias o deseos de los seres humanos. Una vez dado el virus, perjuicios y beneficios se derivarán de ello, sin que preferencias o deseos intervengan. Está en los seres humanos, sin embargo, encontrar qué beneficios o perjuicios se derivan de ello.

Es verdad que dichos perjuicios y beneficios pudieron ser resultado de otros acontecimientos -como el de una guerra, en el caso de las pérdidas humanas y económicas- o el de un acuerdo y una regularización mundial -en el caso del manejo responsable de los medios electrónicos-. Ello no excluye, sin embargo, que no lo sean también del SARS-CoV-2. En ello, preferencias y deseos nos están inmersos. 


\section{Conclusión}

En futuras investigaciones sería importante estudiar, sistemáticamente, el concepto beneficio. Por el tema de este artículo, hemos podido obtener solamente una aproximación de sus diversas definiciones, al partir de una definición básica. Sin embargo, sería filosóficamente relevante proporcionar y evaluar criterios, encontrando un mejor entendimiento de este concepto que tanto repercute en ética, economía, política, psicología, entre otras disciplinas.

De acuerdo a mi investigación, no hay un estudio actual que examine el concepto beneficio. Lo que hay es el uso de dicho concepto en diversas disciplinas, pero no un estudio riguroso que considere sus condiciones necesarias y suficientes, si puede establecerse algo como ello. Por ejemplo, en una de las paradojas más desafiantes en la historia de la filosofía, a saber: "vicio privado, beneficio público", Bernard Mandeville asume beneficio como el bien proporcionado a un grupo de personas, sin elaborar un análisis sistemático sobre dicho concepto ${ }^{14}$.

En la literatura actual tampoco hay análisis alguno sobre el concepto beneficio. Para corroborar esto, basta mirar dos enciclopedias electrónicas ampliamente consultadas: Internet Encyclopedia of Philosophy y Stanford Encyclopedia of Philosophy. En ellas podemos rastrear artículos que estudian conceptos como: confianza, gratitud, riesgo, justicia, pero no beneficio. Sería fructífero, entonces, llevar una investigación única sobre este concepto, y sus repercusiones en diferentes disciplinas.

Sería interesante investigar también por qué las instancias públicas y privadas no habían proporcionado con anterioridad una información que fomentara o incrementara la confianza y la responsabilidad en los medios electrónicos, siendo un medio importante en la vida de los seres humanos en las últimas décadas; o por qué se ha creído hasta ahora que los medios electrónicos perjudican exclusivamente la interacción social y la comunicación de las personas, cuando es claro que las favorece, como se muestra ahora en este confinamiento por causa del SARS-CoV-2.

En este confinamiento, los medios electrónicos han permitido al ser humano cursos diversos: continuar las relaciones sociales y sentimentales; seguir educando y especializando personas; percibir ingresos económicos no

14 Mandeville, Bernard. The Fable of the Bees. England: Penguin Books. 1970. 
solamente en ámbitos educativos, sino también en otros diferentes, como el de la psicología, la comunicación, la política y la economía, entre otros.

Los medios electrónicos han proporcionado, en suma, un mundo virtual que no se aleja del físico, sino que lo acompaña, favoreciendo la calidad de vida de los seres humanos. Esto es el resultado de que los ciudadanos hayan incrementado su confianza en el uso de los medios electrónicos, al haber sido informados, generando también responsabilidad. Confiando en los medios electrónicos, y siendo responsable en su uso, las personas comienzan a vivir una realidad virtual que no se aleja de la física, sino que la acompaña. Estos son los beneficios que ha traído como consecuencia el SARS-CoV-2. 